\title{
Using Near Infrared Spectroscopy to Quickly Analyze Different Nitrogens during the Shortcut Biological Removal of Nitrogen from a Polluted River
}

\author{
Jian Huang1, 2, Ming Li ${ }^{1,2}$, Hua Zhang1,2*, Yong Zhang1, 2, Jiu Liu ${ }^{3}$, \\ Weiwei Sun ${ }^{1,2}$, Tao Ma ${ }^{1,2}$, Yiqi Xu ${ }^{1,2}$, Xinrui Yuan ${ }^{1,2}$ \\ ${ }^{1}$ Key Laboratory of Anhui Province of Water Pollution Control and Wastewater Reuse, School of Environment \\ and Energy Engineering, Anhui Jianzhu University, Hefei, China \\ ${ }^{2}$ School of Environmental and Energy Engineering, Anhui Jianzhu University, Hefei, P.R. China \\ ${ }^{3}$ Anhui Zhonghuan Environmental Protection Technology Co., Ltd
}

Received: 6 April 2018

Accepted: 10 June 2018

\begin{abstract}
During shortcut biological nitrogen removal in a polluted river, total nitrogen, ammonia nitrogen and nitrite nitrogen were quantified by near infrared spectroscopy and the synergy interval partial least squares (siPLS) algorithm. Spectral data of 138 water samples were obtained with a near infrared spectrometer. In addition, the real values of total nitrogen, ammonia nitrogen and nitrite nitrogen were measured with traditional chemical methods. SiPLS analysis models of total nitrogen, ammonia nitrogen and nitrite nitrogen were built through the siPLS algorithm based on spectral data and real values. The results obtained from the siPLS analysis model of total nitrogen revealed that, when the full spectra were divided into 19 intervals, the combination of the $7^{\text {th }}, 12^{\text {th }}$ and $19^{\text {th }}$ subintervals yielded the best model. The correction coefficient $\left(R_{\mathrm{p}}\right)$ is 0.9931 , with the root mean squared error of calibration (RMSECV) being 1.7869. The results obtained from the siPLS analysis model of ammonia nitrogen indicated that, when the full spectra were divided into 16 intervals, the combination of the $1^{\text {st }}, 7^{\text {th }}, 15^{\text {th }}$ and $16^{\text {th }}$ subintervals yielded the best model. The $R_{\mathrm{p}}$ is 0.9947 and the RMSECV is 1.3419. For nitrite nitrogen, the siPLS analysis model indicated that, when the full spectra were divided into 16 intervals, the combination of the 7th and the 11th subintervals yielded the best model. The $R_{\mathrm{p}}$ and RMSECV was 0.9951 and 1.0518. These findings demonstrated that the proposed approach may effectively analyze the concentrations of total nitrogen, ammonia nitrogen and nitrite nitrogen during the treatment of a polluted river based on shortcut biological nitrogen removal. This approach,
\end{abstract}

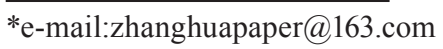


which is based on near infrared spectroscopy, is fast and accurate for the detection of different types of nitrogen in water.

Keywords: shortcut biological nitrogen removal; polluted river; near infrared spectroscopy; synergy interval partial least squares

\section{Introduction}

Nitrogen is the main pollutant causing river eutrophication, and hence the removal of nitrogen is essential for the functional recovery of river water [1-3]. Shortcut biological nitrogen removal is an efficient and energy-saving biological process of nitrogen removal. Shortcut biological nitrogen removal is achieved through controlling environmental conditions and preventing further oxidation of nitrite nitrogen. This process can save $40 \%$ of carbon and $25 \%$ of oxygen compared with the whole biological nitrogen removal process [4-6]. However, for polluted rivers, shortcut biological nitrogen removal has not been much studied in recent years. In addition, shortcut biological nitrogen removal may easily change into full biological nitrogen removal. Therefore, timely detection of nitrogen indicators is quite important for the regulation of the shortcut biological nitrogen removal process [7].

The traditional methods of detecting nitrogen indicators usually involve complex procedures and consume large amounts of chemicals, potentially leading to secondary pollution. Furthermore, different chemical analysis methods are needed for different nitrogen indicators [8-10]. Therefore, a novel method capable of rapid detection of different nitrogen indicators will considerably improve efficiency. As a new method, near infrared spectroscopy has many advantages, such as a simple process, low price, high efficiency and unwanted agents. And crucially, near infrared spectroscopy is capable of simultaneous analysis of many components. In recent years, near infrared spectroscopy coupled with chemometrics has been widely applied as a quantitative analysis tool in many fields, such as food, medicinal materials, microbial metabolites and so on [11-14]. It has been reported that near infrared spectroscopy has been applied to the quantitative analysis of components in water $[15,16]$. But so far, this approach has been rarely applied to the quantitative analysis of total nitrogen, ammonia nitrogen and nitrite nitrogen during the shortcut biological nitrogen removal in a polluted river.

However, spectral data usually contain some random noises that are produced during the generation and the transmission of near infrared spectral signal, and may reduce the reliability of response variable, and interfere with the detection of the relationship between the spectral data and the effective component content of the samples [17]. To reduce these noises, it is necessary to properly pretreat the data before establishing the quantitative analysis model based on near infrared spectroscopy $[18,19]$. As to this issue, wavelet transform denoising provides an effective method for spectral preprocessing. Based on the differences in frequency between the spectral signal and the noise signal, the wavelet domain denoising method can effectively eliminate noise by setting thresholds on different frequency scales. After preprocessing, the effective spectral information was extracted, and the precision of quantitative analysis model is improved [20-24].

Synergy interval partial least squares (siPLS) is a chemometric method based on interval partial least squares (iPLS) [25-28]. The iPLS chooses only a good subinterval to establish a quantitative analysis model, ignoring the information of all other subintervals. Therefore, some useful information in other subintervals might be lost [29-33]. To mend this flaw, the siPLS algorism is developed, which considers all combination of intervals and selects the optimal combination of subintervals. Therefore, siPLS has a wider coverage of spectral information. Then the partial least square model of each combination is built, and the corresponding root mean square error of cross validation (RMSECV) is calculated [34-36]. The combination of subintervals with minimal RMSECV is optimal, and the model based on this optimal combination is considered to be the best [37].

In this study, a shortcut biological nitrogen removal process was used to treat the polluted river. Wavelet denoising method was used to preprocess spectral data of water samples. SiPLS was used to select the optimal combination of subintervals, and siPLS analysis models were built for total nitrogen, ammonia nitrogen and nitrite nitrogen. It is hoped that a polluted river can be effectively treated through the shortcut biological nitrogen removal process, and that a method found as capable of rapid and accurate measurement of the total nitrogen, ammonia nitrogen and nitrite nitrogen.

\section{Material and Methods}

\section{Collecting and Testing Experimental Samples}

In this experiment, water samples were collected from the Shiwuli River in southwestern Anhui Province, a river where nitrogen content had seriously exceeded the standards. Meanwhile, the surface layer of river sediment was also sampled at a depth of $30 \mathrm{~cm}$ with a piston column sampler and kept away from light. These samples were taken back to the laboratory to conduct small-scale experiments. The location of the sampling is shown in Fig. 1. The reactor used in the experiments was made of rectangular organic glass 


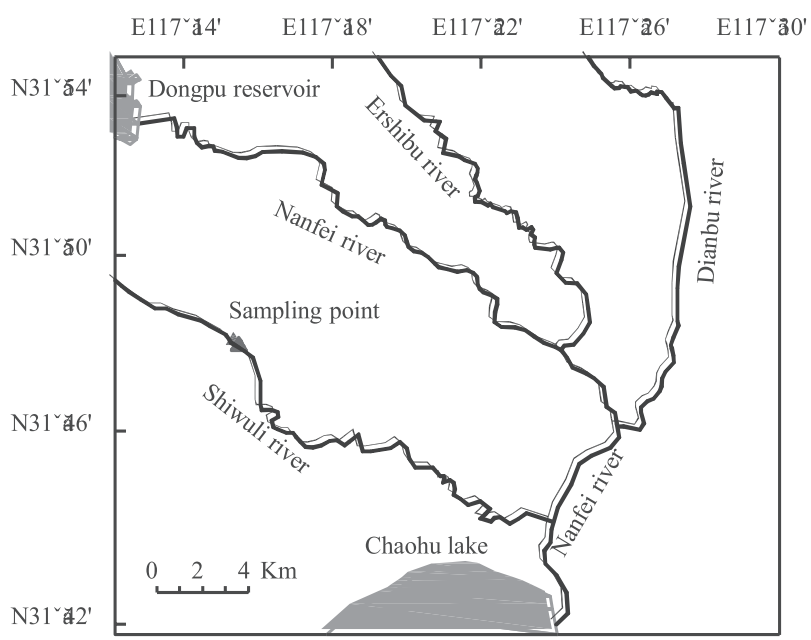

Fig. 1. Location of sampling.

$(\mathrm{L} \times \mathrm{B} \times \mathrm{H}=21 \times 20 \times 51 \mathrm{~cm})$. The river water and sediment were put into the reactor, where the depth of water was $27 \mathrm{~cm}$ and the sediment layer was $9 \mathrm{~cm}$ thick. The lower part of the reactor was coated with black film to shield it from light. After the sediment was deposited, the overlying water was aerated by electromagnetic air pump. According to environmental quality standards of surface water in China, the dissolved oxygen should be at least $5 \mathrm{mg} \mathrm{L}^{-1}$ in the Shiwuli River. Therefore, the dissolved oxygen in this experiment should be controlled as $5.5 \mathrm{mg} \mathrm{L}^{-1}$. This study lasted for $138 \mathrm{~d}$.

The water was sampled every day, and 138 water samples were collected. The spectral data of all the water samples were obtained with a Fourier transform near-infrared spectroscopy apparatus (MPA, Bruker, Ettlingen, Germany). The real concentrations of total nitrogen, ammonia nitrogen, nitrate nitrogen and nitrite nitrogen of water samples were measured by alkaline potassium persulfate digestion ultraviolet spectrophotometric method, nessler's reagent spectrophotometry, ultraviolet spectrophotometry and the spectrophotometric method.

\section{Establishing the Method of siPLS Analysis Model}

All the water samples were divided into two groups. One group had 116 water samples that were employed as calibration samples to establish the siPLS analysis models. The remaining 22 water samples were used as independent test sets to test the siPLS analysis models. The modeling procedures are as follows: firstly, the original spectra of 116 samples were pretreated with wavelet transform denoising method; secondly, the full spectral region was divided into $10,11 \ldots .$. , and 20 intervals respectively by siPLS algorithm; then partial least squares regression models were established for different combinations of 2, 3 or 4 subintervals under a certain interval. After that, the optimal combination of subintervals was chosen by comparing the RMSECVs of models of all combinations. The optimal model is the model built on the optimal combination with the minimum RMSECV. The RMSECV and the $R_{c}$ are the evaluation indexes of each combination. The formulas to calculate RMSECV and $R_{c}$ are as follows [38]:

$$
\begin{gathered}
R_{c}=\sqrt{1-\frac{\sum_{\mathrm{i}=1}^{\mathrm{m}}\left(x_{i}-x_{i}^{\prime}\right)^{2}}{\sum_{\mathrm{i}=1}^{\mathrm{m}}\left(x_{i}-\bar{x}\right)^{2}}} \\
\text { RMSECV }=\sqrt{\frac{\sum_{\mathrm{i}=1}^{\mathrm{m}}\left(x_{i}-x_{i}^{\prime}\right)^{2}}{m-1}}
\end{gathered}
$$

...where $m$ is the number of the calibration samples; $x_{i}$ is the real value of the calibration samples; $x_{i}{ }^{\prime}$ is the value corrected by siPLS; and $\bar{x}$ is the average of the real values of the calibration samples.

The 22 independent samples were used to test the robustness of the siPLS analysis models. For total nitrogen, ammonia nitrogen and nitrite nitrogen, values predicted by siPLS were compared with the real values obtained through traditional chemical methods. The RMSEP value and $R_{p}$ are the evaluation indexes of siPLS analysis models. The RMSEP and $R_{p}$ are calculated as follows [39, 40]:

$$
\begin{gathered}
R_{p}=\sqrt{1-\frac{\sum_{i-1}^{n}\left(y_{i}-y_{i}^{\prime}\right)^{2}}{\sum_{i-1}^{n}\left(y_{i}-\bar{y}\right)^{2}}} \\
\operatorname{RMSEP}=\sqrt{\frac{\sum_{\mathrm{i}=1}^{\mathrm{n}}\left(y_{i}-y_{i}^{\prime}\right)^{2}}{n-1}}
\end{gathered}
$$

...where $n$ is the number of the 22 independent samples; $y_{i}$ is the real value of the 22 independent samples; $y_{i}{ }^{\prime}$ is the value predicted by siPLS analysis models; and $\bar{y}$ is the average of the real values of the 22 independent samples.

\section{Results and Discussion}

\section{Nitrogen Change during Shortcut Biological Nitrogen Removal}

Fig. 2 shows the changes of total nitrogen, ammonia nitrogen, nitrate nitrogen and nitrite nitrogen. As can be seen in Fig. 2, there is generally a declination in the concentration of ammonia nitrogen, which finally decreases to $0.57 \mathrm{mg} / \mathrm{L}$. However, there are also fluctuations during the process. At the beginning of stabilization (12 d), ammonia nitrogen increased due to the transformation of organic nitrogen and the release of nitrogen in the sediment. During subsequent stages of reaction, ammonia nitrogen decreased during aeration stage, but increased during non-aeration stage. Nitrite nitrogen increased during aeration stage but decreased 


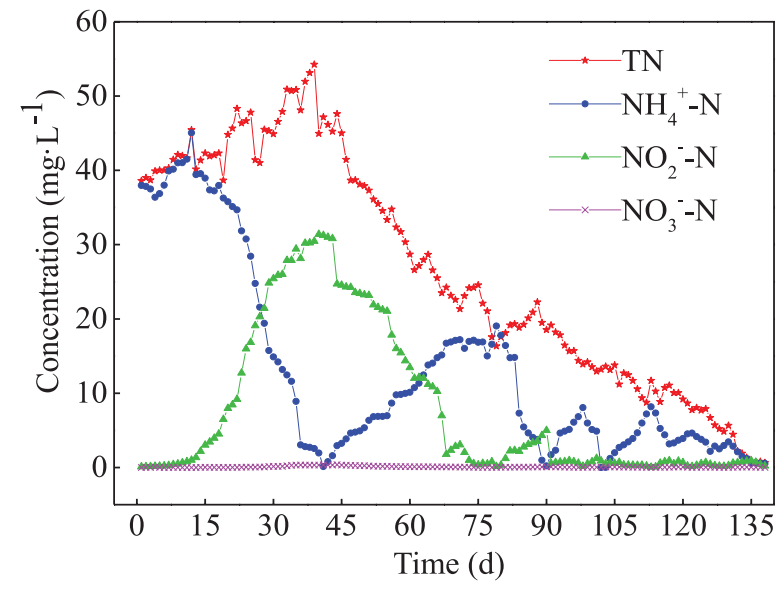

Fig. 2. Changes of nitrogen during shortcut biological removal of nitrogen.

during non-aeration stage, and finally the concentration of nitrite nitrogen was $0.22 \mathrm{mg} / \mathrm{L}$. The concentration of nitrate nitrogen did not change much $(0 \sim 0.38 \mathrm{mg} / \mathrm{L})$, and finally became $0.021 \mathrm{mg} / \mathrm{L}$. Total nitrogen had a decreasing trend in general. But at the initial stage (38 d), total nitrogen increased due to a release of nitrogen from sediment. At the end of the experiment, total nitrogen was $0.64 \mathrm{mg} / \mathrm{L}$. After repeated aeration and non-aeration, shortcut biological nitrogen removal was achieved during treatment of the polluted river.

\section{Preprocessing of Near Infrared Spectra}

Fig. 3 shows the near infrared spectra of water samples during shortcut nitrogen removal, and the spectral wave number is $4000 \sim 12500 \mathrm{~cm}^{-1}$. As can be seen in Fig. 3, the near infrared spectra of different water samples are similar, and each near-infrared spectrum fluctuates within a certain range. However, near infrared spectra fluctuates greatly in the ranges between 4000 and $5400 \mathrm{~cm}^{-1}$ and between 6500 and $7000 \mathrm{~cm}^{-1}$, which may be due to the random noise in the generation of near infrared spectra. Therefore, it is necessary to preprocess the near infrared spectra.

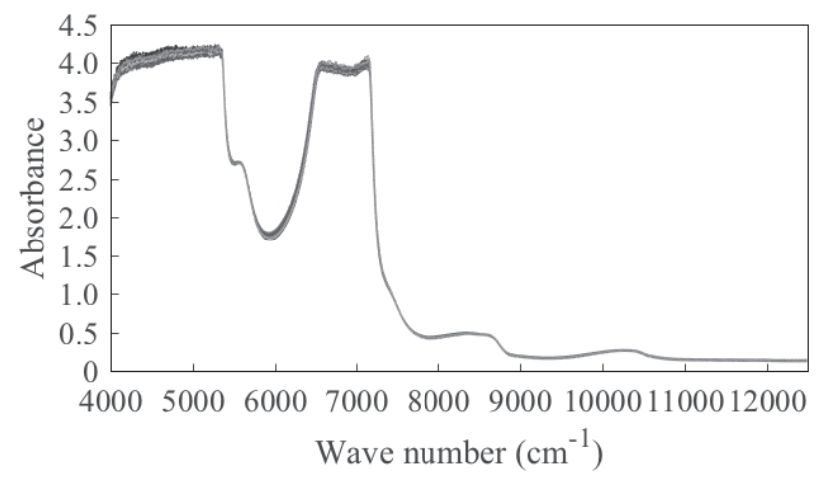

Fig. 3. Near infrared spectra of water samples.

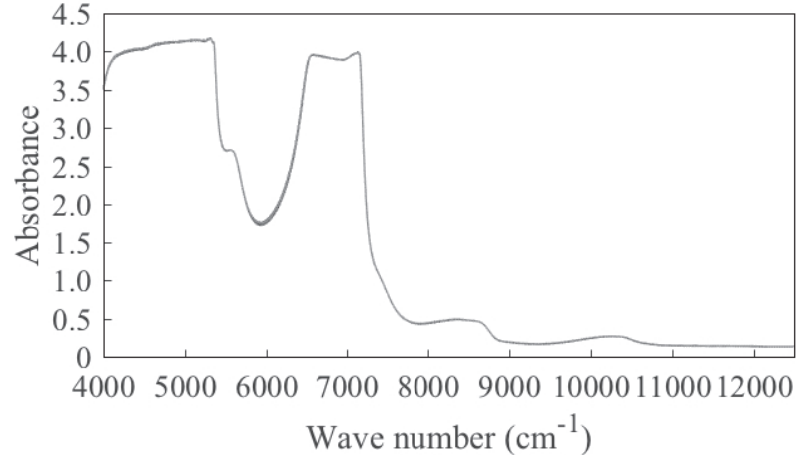

Fig. 4. Near infrared spectra after wavelet denoising.

The wavelet transform denoising method was employed to preprocess the near infrared spectra, and the result is shown in Fig. 4. As can be seen in Fig. 4, the overall shape of the spectra does not change after preprocessing. However, the burrs of the spectra decrease significantly, and the spectra are smoother. These results indicate that the wavelet denoising method has effectively removed random noises, which may also reduce the effect of these random noises on the relationship between the spectral data and the effective component content of the samples. Therefore, the data involved in the modeling will be more stable and reliable.

\section{SiPLS Analysis Model of Total Nitrogen}

With the siPLS method, the preprocessed full spectra were divided into 10 20 intervals. In addition, under a certain interval, combinations of subintervals are formed, which were composed of 2, 3 and 4 subintervals. Then for each combination, the analysis model of partial least squares was built to investigate the influence of different numbers of interval and different combinations on the performance of the siPLS analysis model of total nitrogen. As can be seen from Table 1, siPLS analysis model was affected by the numbers of intervals and the different combinations. The best siPLS analysis model of total nitrogen was found in the combination of the $7^{\text {th }}$, the $12^{\text {th }}$, and the $19^{\text {th }}$ subintervals when the full spectra were divided into 19 intervals. The corresponding principal component was 11. As shown in Fig. 5, the spectral wavenumbers of the $7^{\text {th }}, 12^{\text {th }}$ and $19^{\text {th }}$ interval are $6880 \sim 7124,8418 \sim 9361$, $11602 \sim 12046 \mathrm{~cm}^{-1}$, respectively.

The siPLS analysis model of total nitrogen was built on the basis of the spectral data of the $7^{\text {th }}$, the $12^{\text {th }}$ and the $19^{\text {th }}$ subintervals, as shown in Fig. 6, where the $R_{\mathrm{c}}$ between the corrected value and the real value is 0.9931 and the RMSECV is 1.7869. The experimental results show that siPLS analysis model of total nitrogen has good effect. 
Table 1. Optimal siPLS analysis models of total nitrogen for each number of intervals.

\begin{tabular}{|c|c|c|c|c|c|c|}
\hline \multirow{2}{*}{$\begin{array}{c}\text { Number } \\
\text { of intervals }\end{array}$} & \multirow{2}{*}{$\begin{array}{c}\text { Combination } \\
\text { subinterval }\end{array}$} & \multirow{2}{*}{$\begin{array}{c}\text { Number of principle } \\
\text { components }\end{array}$} & \multicolumn{2}{|c|}{ Calibration set } & \multicolumn{2}{|c|}{ Validation set } \\
\cline { 4 - 7 } & RMSECV & $R_{\mathrm{c}}$ & RMSEP & $R_{\mathrm{p}}$ \\
\hline 10 & $1,4,6$ & 13 & 1.8293 & 0.9927 & 2.7879 & 0.9681 \\
\hline 11 & 4,7 & 14 & 1.8226 & 0.9928 & 2.7863 & 0.9677 \\
\hline 12 & $1,10,11,12$ & 13 & 1.8298 & 0.9927 & 2.7854 & 0.9673 \\
\hline 13 & 1,10 & 13 & 1.8240 & 0.9928 & 2.7841 & 0.9651 \\
\hline 14 & $1,5,8$ & 12 & 1.8143 & 0.9928 & 2.7737 & 0.9649 \\
\hline 15 & 1,4 & 12 & 1.8244 & 0.9928 & 2.7834 & 0.9658 \\
\hline 16 & 6,9 & 12 & 1.8088 & 0.9929 & 2.7651 & 0.9796 \\
\hline 17 & $1,6,7$ & 15 & 1.8214 & 0.9928 & 2.7594 & 0.9791 \\
\hline 18 & 15,16 & 16 & 1.8181 & 0.9928 & 2.7593 & 0.9789 \\
\hline 19 & $7,12,19$ & 11 & 1.7869 & 0.9931 & 2.7431 & 0.9837 \\
\hline 20 & $3,7,13$ & 13 & 1.7895 & 0.9930 & 2.7543 & 0.9834 \\
\hline
\end{tabular}

\section{SiPLS Analysis Model of Ammonia Nitrogen}

Similarly, the preprocessed spectra were also divided into 10 20 intervals to establish siPLS analysis models of ammonia nitrogen. For each number of interval, siPLS analysis models were established for different combinations of subintervals. Then the optimal siPLS analysis model of ammonia nitrogen was selected.

Table 2 indicates the optimal siPLS analysis model of ammonia nitrogen for different numbers of intervals. It can be seen from Table 2 that the siPLS analysis model of ammonia nitrogen was affected by both the number of the interval and the combination of subintervals. Among these models that are optimal for different numbers of intervals, the best siPLS analysis model of ammonia nitrogen was found in the combination of the $1^{\text {st }}, 7^{\text {th }}, 15^{\text {th }}$ and $16^{\text {th }}$ subintervals,

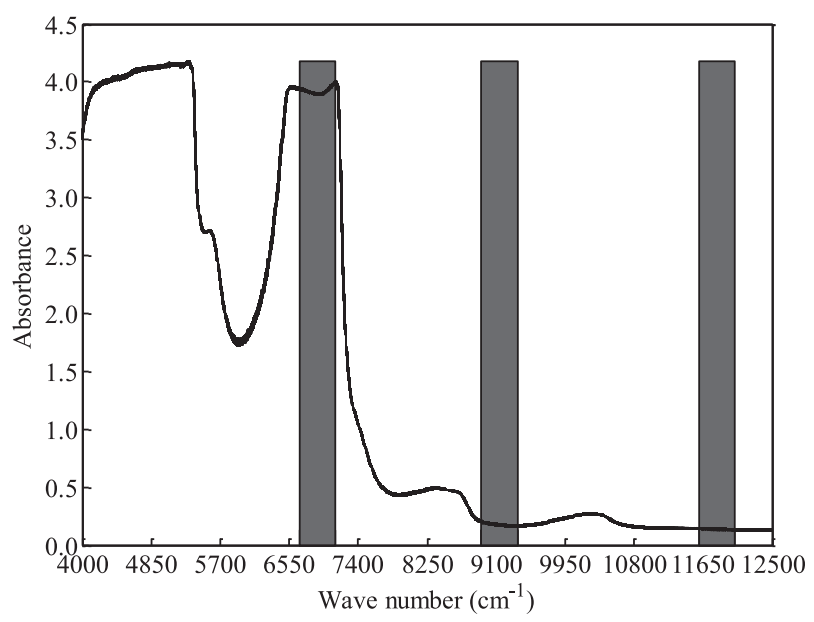

Fig. 5. Combination of the $7^{\text {th }}, 12^{\text {th }}$ and $19^{\text {th }}$ that yielded the best model of total nitrogen. when the spectra were divided into 16 intervals and the principle component number was 15. In Fig. 7, the wavenumber ranges of the $1 \mathrm{st}, 7^{\text {th }}, 15^{\text {th }}$, and $16^{\text {th }}$ subintervals were respectively 4000 4524, 7174 7702, $11432 \sim 11964$ and $11964 \sim 12500 \mathrm{~cm}^{-1}$. It can be seen from Fig. 8 that the $R_{\mathrm{c}}$ and the RMSECV were 0.9947 and 1.3419 .

\section{SiPLS Analysis Model of Nitrite Nitrogen}

The siPLS analysis models of nitrite nitrogen were built in the same way as the siPLS analysis models of ammonia nitrogen and total nitrogen. For each number of intervals, the partial least squares regression model was built for different combinations of subintervals (2, 3 and 4) so that the best model can be found through comparing the RMSECV of the model, as seen in Table 3, which indicates that when the full spectra were divided into 19 and the principle component number was 13 , the combination of the $7^{\text {th }}$ and $11^{\text {th }}$

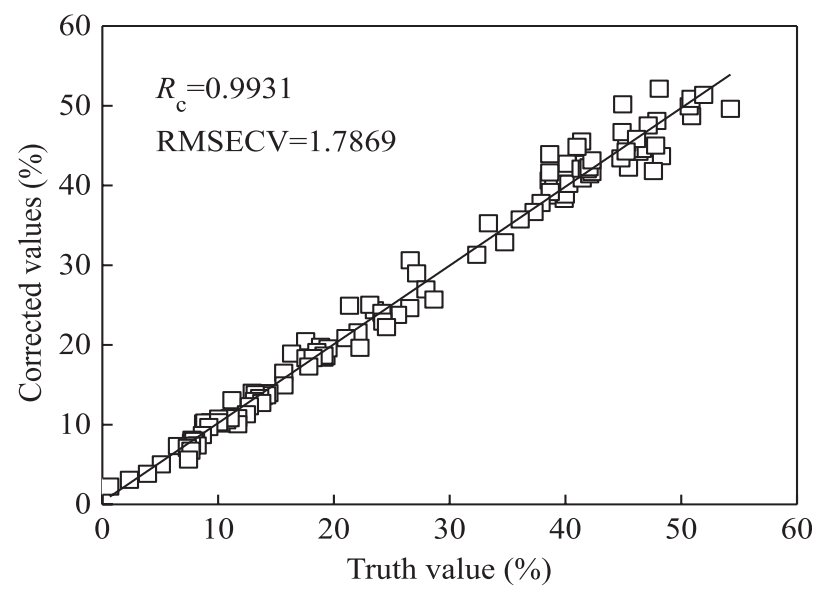

Fig. 6. SiPLS analysis model of total nitrogen. 
Table 2. Optimal siPLS analysis model of ammonia nitrogen for each number of intervals.

\begin{tabular}{|c|c|c|c|c|c|c|}
\hline \multirow{2}{*}{$\begin{array}{c}\text { Number } \\
\text { of intervals }\end{array}$} & \multirow{2}{*}{$\begin{array}{c}\text { Combination } \\
\text { subinterval }\end{array}$} & \multirow{2}{*}{$\begin{array}{c}\text { Number of principle } \\
\text { component }\end{array}$} & \multicolumn{2}{|c|}{ Calibration set } & \multicolumn{2}{|c|}{ Validation set } \\
\cline { 3 - 7 } & $1,4,9$ & RMSECV & $R_{\mathrm{c}}$ & RMSEP & $R_{\mathrm{p}}$ \\
\hline 10 & $4,5,10,11$ & 15 & 1.3634 & 0.9946 & 1.7423 & 0.9779 \\
\hline 11 & $3,4,9,11$ & 16 & 1.3601 & 0.9946 & 1.7286 & 0.9871 \\
\hline 12 & $1,5,13$ & 15 & 1.3519 & 0.9947 & 1.7274 & 0.9850 \\
\hline 13 & $5,6,11,14$ & 16 & 1.3507 & 0.9947 & 1.7278 & 0.9883 \\
\hline 14 & 1,6 & 15 & 1.3691 & 0.9945 & 1.7408 & 0.9857 \\
\hline 15 & $1,7,15,16$ & 15 & 1.3419 & 0.9947 & 1.7255 & 0.9908 \\
\hline 16 & $1,6,8$ & 15 & 1.3640 & 0.9946 & 1.7363 & 0.9799 \\
\hline 17 & $1,7,8,13$ & 15 & 1.3654 & 0.9945 & 1.7387 & 0.9846 \\
\hline 18 & $1,8,13,15$ & 15 & 1.3529 & 0.9946 & 1.7295 & 0.9877 \\
\hline 19 & 1,2 & 15 & 1.3670 & 0.9945 & 1.7269 & 0.9896 \\
\hline 20 & & & & & & \\
\hline
\end{tabular}

subintervals yielded the best siPLS analysis model of nitrite nitrogen. Fig. 9 indicates that the wave number ranges of the $7^{\text {th }}$ and the $11^{\text {th }}$ subintervals were 6880 7124 and 8470 8914 $\mathrm{cm}^{-1}$, respectively.

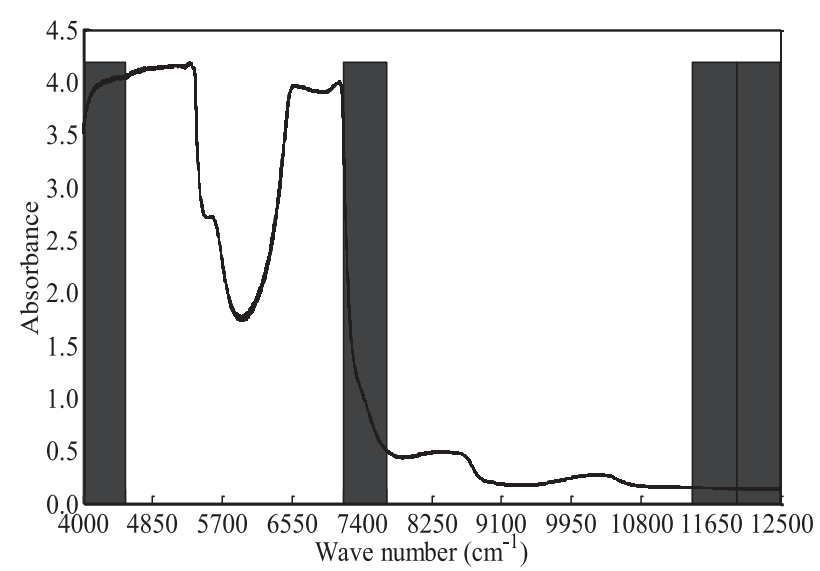

Fig. 7. Combination of the $1^{\text {st }}, 7$ th, $15^{\text {th }}$ and $16^{\text {th }}$ subintervals that yielded the best model of ammonia nitrogen.

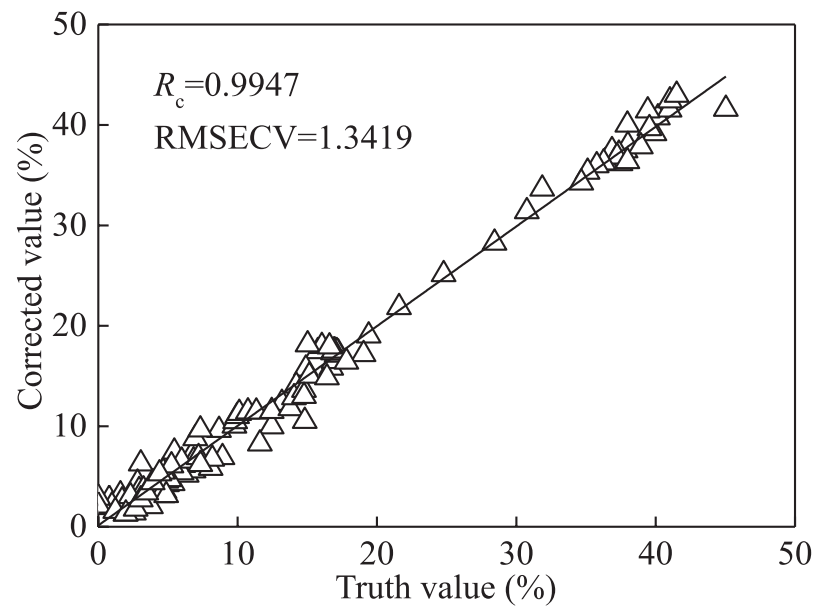

Fig. 8. SiPLS analysis model of ammonia nitrogen.
The siPLS analysis model of nitrite nitrogen is shown in Fig. 10. It can be seen from Fig. 10 that the RMSECV is 1.0518 , and the $R_{\mathrm{c}}$ is 0.9951 . The experimental results

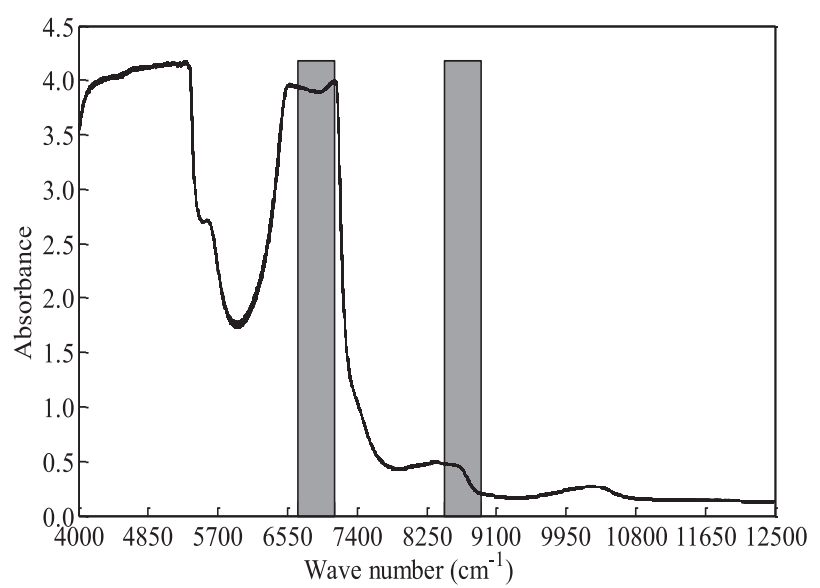

Fig. 9. Combination of the $7^{\text {th }}$ and the $11^{\text {th }}$ subintervals that yielded the best model.

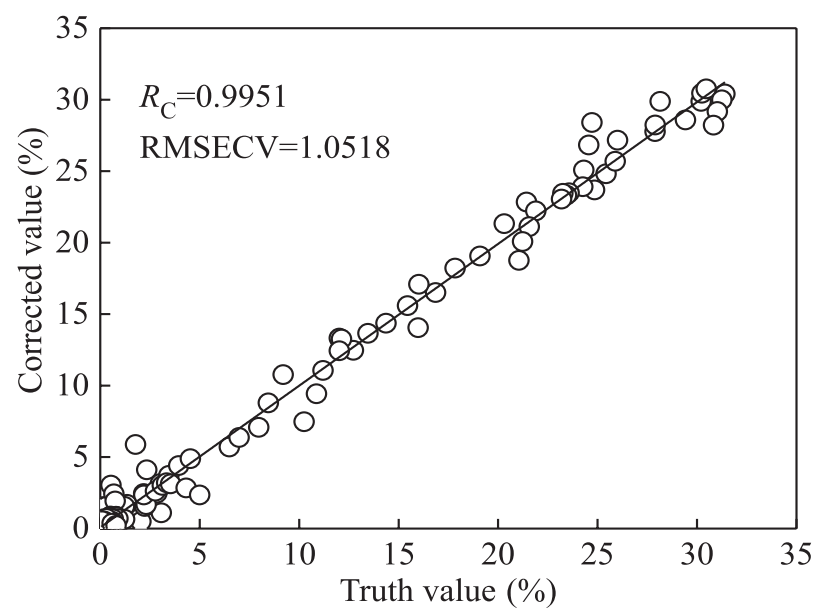

Fig. 10. SiPLS analysis model of nitrite nitrogen. 
Table 3. Optimal siPLS analysis models of nitrite nitrogen for each number of intervals.

\begin{tabular}{|c|c|c|c|c|c|c|}
\hline \multirow{2}{*}{$\begin{array}{c}\text { Number } \\
\text { of intervals }\end{array}$} & \multirow{2}{*}{$\begin{array}{c}\text { Combination } \\
\text { subinterval }\end{array}$} & \multirow{2}{*}{$\begin{array}{c}\text { Number of principle } \\
\text { component }\end{array}$} & \multicolumn{2}{|c|}{ Calibration set } & \multicolumn{2}{|c|}{ Validation set } \\
\cline { 3 - 7 } & $1,4,9,10$ & 14 & 1.0696 & 0.9947 & 1.5072 & 0.9788 \\
\hline 10 & $3,9,10,11$ & 11 & 1.0803 & 0.9949 & 1.5143 & 0.9823 \\
\hline 11 & $1,5,12$ & 14 & 1.0674 & 0.9950 & 1.5068 & 0.9785 \\
\hline 12 & $1,5,13$ & 14 & 1.0742 & 0.9949 & 1.5154 & 0.9841 \\
\hline 13 & 4,10 & 13 & 1.0645 & 0.9950 & 1.5108 & 0.9824 \\
\hline 14 & $4,14,15$ & 12 & 1.0682 & 0.9950 & 1.5122 & 0.9846 \\
\hline 15 & 6,12 & 13 & 1.0578 & 0.9951 & 1.5066 & 0.9865 \\
\hline 16 & $2,6,10$ & 14 & 1.0720 & 0.9949 & 1.5123 & 0.9807 \\
\hline 17 & $5,10,12,13$ & 12 & 1.0581 & 0.9951 & 1.5067 & 0.9796 \\
\hline 18 & 7,11 & 13 & 1.0518 & 0.9951 & 1.5064 & 0.9891 \\
\hline 19 & 6,14 & 11 & 1.0603 & 0.9951 & 1.5069 & 0.9853 \\
\hline 20 & & & & & $R_{\mathrm{p}}$ \\
\hline
\end{tabular}

indicate that the siPLS analysis model of nitrite nitrogen is capable of correct predications.

\section{Validating the SiPLS Analysis Model}

The robustness of siPLS analysis models were tested with the data of the 22 independent samples. The results are presented in Figs 11-13, where the real values were obtained with traditional methods and the predicted values came from these models. Fig. 11 shows the testing result of the siPLS analysis model of total nitrogen. The $R_{\mathrm{p}}$ between the predicted values and the real values is 0.9837 , and the RMSEP is 2.7431 . Fig. 12 indicates the testing result of the siPLS analysis model of ammonia nitrogen. The $R$ between the predicted values and the real values is 0.9908 , and the RMSEP is 1.7255 . Fig. 13 registers the testing result of the siPLS analysis model of nitrite nitrogen. The $R_{\mathrm{p}}$ between the predicted values and the real

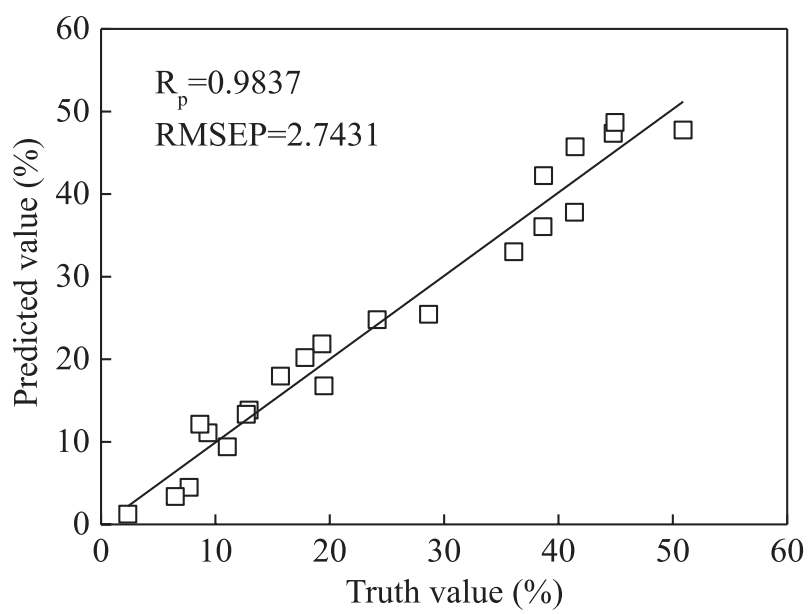

Fig. 11. Test results of siPLS analysis model of total nitrogen.

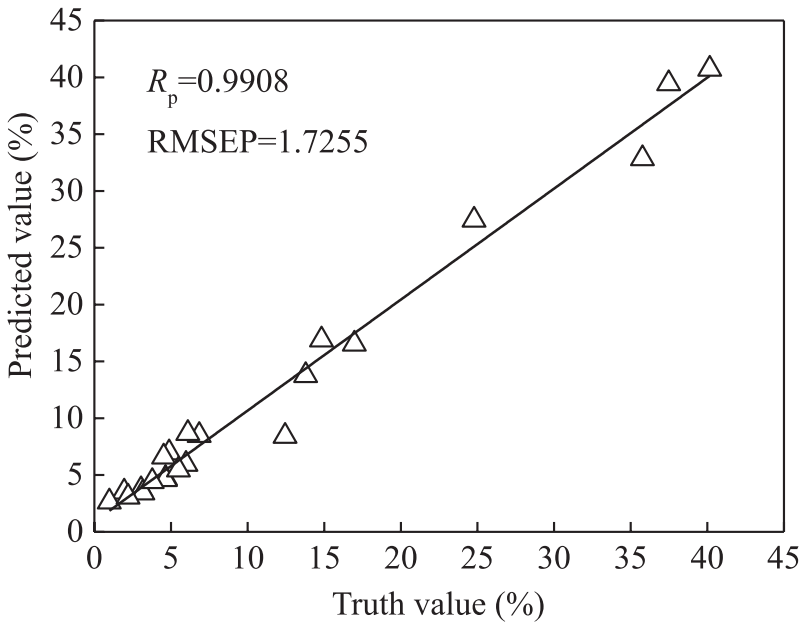

Fig. 12. Test results of siPLS analysis model of ammonia nitrogen.

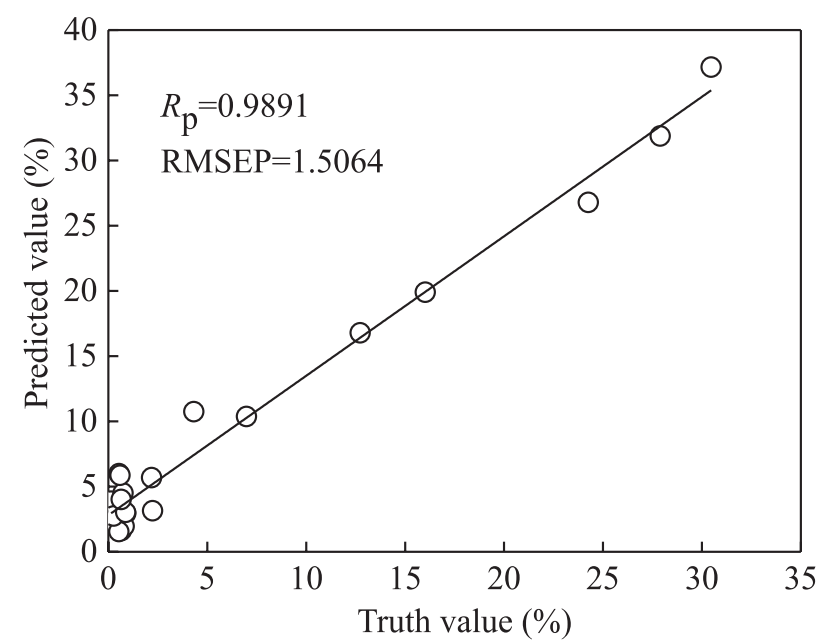

Fig. 13. Test results of siPLS analysis model of nitrite nitrogen. 
values is 0.9891 , with the RMSEP being 1.5064 . These results indicate that siPLS analysis models have good robustness and accurate prediction.

\section{Conclusions}

When shortcut biological nitrogen removal was used in the treatment of a high-nitrogen river, near infrared spectra of water samples were preprocessed with the wavelet denoising method to reduce noise. Based on the siPLS algorithm, the preprocessed spectra were employed to build quantitative analysis models for total nitrogen, ammonia nitrogen and nitrite nitrogen.

The results indicate that these siPLS analysis models of total nitrogen, ammonia nitrogen and nitrite nitrogen, which are built on the basis of the preprocessed spectral data of calibration samples, are capable of accurate prediction. For these models, the $R_{\mathrm{c}}$ are 0.9931 , 0.9947 and 0.9951 respectively, with the RMSECVs being 1.7869, 1.3419 and 1.0518. An independent set of 22 samples were used to test the robustness the siPLS analysis models of total nitrogen, ammonia nitrogen and nitrite nitrogen, and the results indicate that the $R_{\mathrm{p}}$ are $0.9837,0.9908$ and 0.9891 , and the RMSECVs are $2.7431,1.7255$ and 1.5064 , respectively.

In short, the siPLS analysis models of total nitrogen, ammonia nitrogen and nitrite nitrogen provide rapid, simple, time-saving and non-polluting means to quantitatively analyze the contents of total nitrogen, ammonia nitrogen and nitrite nitrogen.

\section{Acknowledgements}

This research was supported by the natural Science Project for Colleges of Anhui Province (KJ2018A0520); Anhui Province Natural Science Foundation (1808085MB34); the Key Projects to Support the Talent for Colleges of Anhui Province (gxyqZD2017059); the Research Projects of Visiting Scholars for Excellent Young and Backbone Talents both at Home and Abroad for Colleges of Anhui Province (gxfx2017054); and the Major Science and Technology Program for Water Pollution Control and Treatment of China (2014ZX07405-003-03).

\section{Conflict of Interest}

The authors declare no conflict of interest.

\section{References}

1. MCDOWELL R.W., HAMILTON D.P. Nutrients and eutrophication: introduction. Marine \& Freshwater Research. 64 (5), III, 2013.
2. NAN X.J., YE L.L., LIU B., LI D.M. Distribution of nitrogen and phosphorus, assessment of eutrophication for water of tongjia river in Nantong. Journal of Nantong University, (1), 40, 2014.

3. ZHANG W.Q., JIN X., LIU D., LANG C., SHAN B.Q. Temporal and spatial variation of nitrogrn and phosphorus and entrophication assessment for a typical arid rivalFuyang River in northern China. Journal of Environmental Science. (5), 41, 2017.

4. HOU J., XIA L., MA T., ZHANG Y., ZHOU Y., HE X. Achieving short-cut nitrification and denitrification in modified intermittently aerated constructed wetland. Bioresource technology. 232, 10, 2017.

5. SUI Q., JIANG C., YU D., CHEN M., ZHANG J., WANG Y., WEI Y., Performance of a sequencing-batch membrane bioreactor (SMBR) with an automatic control strategy treating high-strength swine wastewater. Journal of hazardous materials. 342 (1), 210, 2017.

6. YAO S., CHEN L., GUAN D., ZHANg Z., TIAN X., WANG A., WANG G., YAO Q., PENG D., LI J. On-site nutrient recovery and removal from source-separated urine by phosphorus precipitation and short-cut nitrificationdenitrification. Chemosphere. 175 (5), 210, 2017.

7. LIU M., LIU T., PENG Y., WANG S., XIAO H. Effect of salinity on $\mathrm{N}_{2} \mathrm{O}$ production during shortcut biological nitrogen removal from landfill leachate. Journal of Bioscience \& Bioengineering. 117 (5), 582, 2014.

8. REILlY A.O., COFFEY R., GOWEN A., CUMMINS E. Evaluation of near-infrared chemical imaging for the prediction of surface water quality parameters. International Journal of Environmental Analytical Chemistry. 95 (5), 403, 2015.

9. FANG L.G., LI J.X., LIU Z.B., TANG C.B., LIANG $Z$., Online evaluation of water quality by mid-infrared spectroscopy in river network areas of Suzhou City. Journal of Applied Sciences, 13(10), 2013.

10. CHEN L., XING L., HAN L. Review of the application of near-infrared spectroscopy technology to determine the chemical composition of animal manure. Journal of Environmental Quality. 42 (4), 1015, 2013.

11. YANG R.J, LIU R., XU K.X., YANG Y.R. Quantitative analysis of melamine by multi-way partial least squares model with two-dimensional near-infrared correlation spectroscopy. SPIE BiOS. (1), 393, 2014.

12. FANG H.W., ZENG A.M., JIANG, X.M. ZHU A.L., YANG Y. Application of near-infrared spectroscopy combined with chemometrics in food adulteration detection. Journal of Food Safety \& Quality. (5), 427, 2012.

13. ZHANG Y., XIE Y.L., SUN S.M. Application of nearinfrared spectroscopy combined with chemometrics in oil detection. Cereals \& Oils. (1), 66, 2015.

14. BORILLE B.T., MARELO M.C., ORTIZ R.S., MARIOTTI K.C., FERRAO M.F., LIMBERGER R.P. Near infrared spectroscopy combined with chemometrics for growth stage classification of cannabis cultivated in a greenhouse from seized seeds. Spectrochimica Acta Part A Molecular \& Biomolecular Spectroscopy. 173, 318016.

15. SHEN Q.P., ZHANG T., LIU C.B., PEI H.E., WANG K.M., YANG G.Y., LIU Z.H. Research advances in application of quantitative analysis method of near infrared spectroscopy in chemical components of tobacco and cigarette smoke. Guangdong Agricultural Sciences, (4), 77, 2015.

16. MACFHIONNGHAILE P., HU Y., MCARDLE P., ERXLEBEN A. A comprehensive near infrared spectroscopic study of the limits of quantitative analysis 
of sulfathiazole polymorphism. Journal of Near Infrared Spectroscopy. 21 (1), 55, 2013.

17. OSAWA T., ASANO H., MIZONO T., NOZAWA A., TANAKA H., NOMURA S., OKAZAKI T., IDE H. Physiological and psychological evaluations in low- and high-frequency noise using near-infrared spectroscopy. Artificial Life \& Robotics. 21 (1), 5, 2016.

18. YU L.Y., XIE S.F., ZHANG M., XIANG B.R. Quantitative determination of gliclazide in plasma by near-Infrared spectroscopy compared with tailoring noise frequency spectrum. Journal of AOAC International. 201.

19. MAZZILO M., MELLO D., BARBARINO P.P., ROMEO M., MUSIENKO Y., SCIUTO A., LIBERTINO S., LOMBARDO S., FALLICA G. Noise Reduction in Silicon Photomultipliers for Use in Functional Near-Infrared Spectroscopy. IEEE Transactions on Radiation \& Plasma Medical Sciences. 1 (3), 212, 2017.

20. HUANG J., HUANG S., ZHANG H., HUANG X.H., ZHANG Y., WANG M., ZHU J., WANG K. Near infrared spectroscopy analysis of inorganic nitrogen in shortcut nitrification-denitrification based on interval partial least square, China Environmental Science. 35 (7), 2014, 2015.

21. GAO Z.L., YE W.L., ZHENG C.T., WANG Y.D. Waveletdenoising technique in near-infrared methane detection based on tunable diode laser absorption spectroscopy. Optoelectronics Letters. 10 (4), 299, 2014.

22. MAPPE-FOGAING I., JOLY L., DURRY G., DUMELIE N., DECARPENTERIE T., COUSIN J., PARVITTE B., ZENINARI V. Wavelet denoising for infrared laser spectroscopy and gas detection. Applied Spectroscopy. $\mathbf{6 6}$ (10), 700, 2012.

23. ZHENG C.T., YE W.L., HUANG J.Q., CAO T.S., LV M., DANG J.M., WANG Y.D. Performance improvement of a near-infrared $\mathrm{CH} 4$ detection device using waveletdenoising-assisted wavelength modulation technique. Sensors \& Actuators B Chemical. 190 (1), 2492014.

24. DAUBECHIES I. The wavelet transform, time-frequency localization and signal analysis. Journal of Renewable \& Sustainable Energy. 36 (5), 961, 2015.

25. LI Y., GUO M.Y., SHI X.Y., WU Z.S., LI J.Y., MA Q., QIAO Y.J. Online near-infrared analysis coupled with MWPLS and SiPLS models for the multi-ingredient and multi-phase extraction of licorice (Gancao). Chinese Medicine. 10(1), 1, 2015.

26. LI T.H., SHI G.Y., WANG J.M., WANG M., HU J.L. Prediction of lycopene content in late mature tomato based on NIR spectroscopy and siPLS. International Journal of Applied Mathematics \& Statistics. 48 (18), 172, 2013.

27. WANG X.F., BAO Y.F., LIU G.L., LI G., LIN L. Study on the best analysis spectral section of NIR to detect alcohol concentration based on siPLS. Procedia Engineering. 29 (4), 2285, 2012.

28. ZUO X.B., FANG S., LIANg X.L. Synergy interval Partial Least Square (siPLS) with potentiometric titration multivariate calibration for the simultaneous determination of amino acids in mixtures. Advance Journal of Food Science \& Technology. 6 (11), 1209, 2014.

29. GUO H.X., ZHU S.Q., LI Y.P., FANG T., HUANG F.R., ZHENG S.F., CHEN Z.Q. Visible-near infrared spectroscopy modeling on the contents of serum bilirubin based on iPLS and SiPLS. Journal of Optoelectronics Laser. 27 (10), 1136, 2016.

30. ROCHA J.T.D.C., OLIVEIRA L.M.S.L., DIAS J.C.M., PINTO U.B., MARQUES M.D.L.S.P., OLIVEIRA B.P.D., FILGUEIRAS P.R., CASTRO E.V.R., OLIVEIRA M.A.L.D. Sulfur determination in brazilian petroleum fractions by MIR and NIR using PLS associated to variable selection methods (iPLS, siPLS, UVE and GA). Energy \& Fuels, (1), 2015. DOI: 10.1021/acs.energyfuels.5b02463.

31. RUSCHEL C.F.C., HUANG C.T., SAMIOS D., FERRÃO M.F., YAMAMOTO C.I., PLOCHARSKI R.C.B. Environmentally Friendly Determination of Quality Parameters of Biodiesel/Diesel Blends Using Fourier Transform Infrared Spectra, Journal of the American Oil Chemists Society. 92, 309, 2015.

32. SHI J.Y., ZOU X.B., ZHAO J.W., HOLMES M. Near infrared quantitative analysis of total flavonoid content in fresh Ginkgo biloba leaves based on different wavelength region selection methods and partial least squares regression. Journal of Near Infrared Spectroscopy. 20 (2) 295, 2012.

33. LU Y.Z., DU C.W., YU C.B., ZHOU J.M. Determination of nitrogen and oil contents in rapeseeds using infrared photoacoustic spectroscopy combined with iPLS and siPLS. Chinese Journal of Analysis Laboratory. 32 (9), 78, 2013.

34. MAHANTY B., YOON S.U., KIM C.G. Spectroscopic quantitation of tetrazolium formazan in nano-toxicity assay with interval-based partial least squares regression and genetic algorithm. Chemometrics \& Intelligent Laboratory Systems. 154 (3), 16, 2016.

35. JIANG H., LIU G., MEI C., YU S., XIAO X., DING Y. , Measurement of process variables in solid-state fermentation of wheat straw using FT-NIR spectroscopy and synergy interval PLS algorithm. Spectrochimica Acta Part A Molecular \& Biomolecular Spectroscopy. 97, 277, 2012.

36. KANG Q., RU Q., LIU Y., XU L., LIU J., WANG Y., ZHANG Y., LI H., ZHANG Q., WU Q. On-line monitoring the extract process of $\mathrm{Fu}$-fang Shuanghua oral solution using near infrared spectroscopy and different PLS algorithms. Spectrochimica Acta Part A Molecular \& Biomolecular Spectroscopy. 152 (1) 431, 2016.

37. POERIO D.V., BROWN S.D. Stacked interval sparse partial least squares regression analysis. Chemometrics \& Intelligent Laboratory Systems. (7), 49, 2017.

38. JOVIC O. Durbin-Watson partial least-squares regression applied to MIR data on adulteration with edible oils of different origins. Food Chemistry. 213, 791, 2016.

39. PENG H.G., PENG Y.F., ZHANG Y., LUO H.P., Determination of jujube in south xinjiang by near infrared spectroscopy combined with sipls methods. Food Science And Technology. 39 (6), 276, 2014.

40. ZHANG H., QUAN G.J., HUANG J., HUANG X.H., HUANG S., YAN S., LIU P.R., TIAN J.Y. Study on intracelluar polymers using near infrared spectroscopy and extreme laerning machine in denitrifying phosphorus removal process. China Environmental Science. 37 (5), $1823,2017$. 